\title{
Cause-of-death ascertainment for deaths that occur outside hospitals in Thailand: application of verbal autopsy methods
}

\author{
Warangkana Polprasert ${ }^{1}$, Chalapati Rao*2, Timothy Adair², Junya Pattaraarchachai³, Yawarat Porapakkham ${ }^{4}$ and \\ Alan D Lopez 2,5
}

\begin{abstract}
Background: Ascertainment of cause for deaths that occur in the absence of medical attention is a significant problem in many countries, including Thailand, where more than $50 \%$ of such deaths are registered with ill-defined causes. Routine implementation of standardized, rigorous verbal autopsy methods is a potential solution. This paper reports findings from field research conducted to develop, test, and validate the use of verbal autopsy (VA) methods in Thailand.

Methods: International verbal autopsy methods were first adapted to the Thai context and then implemented to ascertain causes of death for a nationally representative sample of 11,984 deaths that occurred in Thailand in 2005. Causes of death were derived from completed VA questionnaires by physicians trained in ICD-based cause-of-death certification. VA diagnoses were validated in the sample of hospital deaths for which reference diagnoses were available from medical record review. Validated study findings were used to adjust VA-based causes of death derived for deaths in the study sample that had occurred outside hospitals. Results were used to estimate cause-specific mortality patterns for deaths outside hospitals in Thailand in 2005.

Results: VA-based causes of death were derived for 6,328 out of 7,340 deaths in the study sample that had occurred outside hospitals, constituting the verification arm of the study. The use of VA resulted in large-scale reassignment of deaths from ill-defined categories to specific causes of death. The validation study identified that VA tends to overdiagnose important causes such as diabetes, liver cancer, and tuberculosis, while undercounting deaths from HIV/ AIDS, liver diseases, genitourinary (essential renal), and digestive system disorders.

Conclusions: The use of standard VA methods adapted to Thailand enabled a plausible assessment of cause-specific mortality patterns and a substantial reduction of ill-defined diagnoses. Validation studies enhance the utility of findings from the application of verbal autopsy. Regular implementation of VA in Thailand could accelerate development of the quality and utility of vital registration data for deaths outside hospitals.
\end{abstract}

\section{Introduction}

Death registration systems in Thailand have improved greatly over the past two decades. In 2005, the national death registration system recorded just more than 395,000 deaths, about 100,000 more than a decade earlier [1]. However, since the majority of deaths (about 65\%) in Thailand occur outside hospitals and in the absence of medical attention, the reliability of causes of death at reg-

* Correspondence: c.rao@sph.uq.edu.au

2 School of Population Health, University of Queensland, Brisbane, Australia Full list of author information is available at the end of the article istration remains uncertain. In most cases, causes of these deaths are recorded by nonmedical civil registrars based on lay reports from relatives, occasionally informed by medical opinion obtained during the illness leading to death [2]. As a result, a very substantial fraction of deaths occurring at home are registered with illdefined causes of death, limiting the utility of registration data for epidemiological research and health policy [3].

An investigation of registered causes of death in Thailand during 1998-1999 confirmed the potential to obtain more accurate information on causes of death through 
verbal autopsy (VA) methods, a process combining household inquiry with a review of medical records, where available $[4,5]$. Building on this previous research, we designed and implemented a nationally representative study utilizing VA methods adapted to the Thai context to ascertain the likely causes of deaths that had occurred outside hospitals during 2005. This article reports on the development of these VA methods for application in Thailand, our principal findings from implementing them in field studies, and their implications for routine monitoring of causes of death in the country.

VA methods include the use of detailed questionnaires administered by local health personnel to collect information from relatives of the deceased on symptoms and events during the illness leading to death. Completed questionnaires are subsequently reviewed by a physician, who derives the probable cause of death from the information recorded during the interview [6]. Although there are several potential sources of bias in verbal autopsies, these methods are increasingly being used to derive cause-specific mortality estimates in populations that do not have complete medical certification of cause of death [7-16]. In view of the potential for bias, VA methods in any population should first be validated to ascertain the performance characteristics of the instrument, in terms of any systematic over- or underestimation of mortality from particular causes. VA methods have been extensively validated for causes of childhood deaths [17-21]. However, validation of VA methods for adult deaths poses several challenges, particularly in terms of obtaining reference diagnoses, as well as in multiple causation and presentation of symptoms, especially for chronic diseases [22-27].

In this paper, we report on findings from the application of VA methods to ascertain causes of death in Thailand. We conducted two studies:

1) field implementation of VA methods to verify registered causes of deaths outside hospitals in the study sample (the verification study).

2) concurrent implementation of the same VA methods (to validate their performance characteristics) on deaths in the study sample that had occurred in hospitals, for which reference diagnoses were available from medical record review (the validation study).

We also report on the application of the validation study results to adjust the VA- based findings from the verification study, yielding adjusted estimates of causespecific mortality for deaths outside hospitals in Thailand. Apart from generating these mortality estimates for health status assessment and planning in Thailand, this study has developed the foundation for strengthening routine cause-of-death ascertainment in Thailand through the capacity that has been built to implement the methods. Wider implementation of these methods over the next decade, with continuous refinement based on field experiences, could substantially improve the utility of registration data for public health policy and research in Thailand.

\section{Methods \\ Study objectives and design}

A cross-sectional study was designed to allow VA methods to be applied to ascertain causes of death in a nationally representative sample of deaths that occurred in Thailand during 2005. The study formed part of a broader research project to estimate cause-specific mortality in Thailand, as described elsewhere [28]. The objectives of this component of the overall project were to:

1. adapt recent international VA standards for implementation in Thailand [29].

2. implement the locally adapted VA methods in the verification and validation arms of the study.

3. utilize these findings to estimate cause-specific mortality fractions for deaths that occur outside hospitals in Thailand.

\section{Local adaptation of VA methods}

VA methods have been applied before in Thailand. Perhaps the most comprehensive application was carried out in 1997-1999 using a questionnaire that consisted of: a checklist of 10 key symptoms; a checklist of common diseases among children as well as maternal conditions and external causes; and space for free-text recording of the illness preceding death as described by relatives of the deceased [4]. Wherever available, medical records pertaining to the deceased were accessed from district and/ or provincial hospitals. Physician reviewers ascertained the most likely cause of death from all evidence available for each death. Causes of death from the study were subsequently used to estimate cause-specific mortality in Thailand [30]. Other smaller studies using personal digital assistant (PDA) devices have been carried out in the Kanchanaburi Demographic Surveillance site in central Thailand [31]. However, upon validation against deaths with reference diagnoses, the accuracy of this tool was disappointing due to the occurrence of false positive or negative responses that did not fit the programmed algorithms.

Building upon these experiences, we first reviewed current VA questionnaires in use in different international statistics and research programs [29,32,33]. Initially, Thai-translated versions of the draft WHO VA questionnaires (for three age groups: <28 days; 29 days -5 years; and 5 years and above) were pilot-tested in a sample of about 400 deaths in Ayuthaya province in central Thailand. Feedback from the pilot study led to modification of the instrument design and development of Thai versions of VA questionnaires for deaths within two specific age 
groups: less than 1 year, and 1 year and above. The broad structure and content of the questionnaires are summarized in Table 1.

\section{Sampling plan}

The detailed sampling plan for the project has been described elsewhere [29]. The estimated total sample size for the study was about 10,000 deaths. A multistage stratified cluster sampling approach was employed to develop a nationally representative sample of deaths from two provinces in each of four regions of Thailand (Northeast, North, Central, and South), as well as in Bangkok. The sample was distributed according to probability proportionate to size (PPS), i.e., number of registered deaths in 2005 across three major strata: region, province, and district. Based on findings from the pilot study and previous research [4], initial PPS regional samples were inflated by $15 \%$ for each of the four regions and by more than $50 \%$ in Bangkok to account for expected losses to follow up. Within each major region, subunits were divided into two strata at the $50^{\text {th }}$ percentile of numbers of registered deaths, with random selection of subunits from each stratum to fulfill the allocated PPS study sample. This form of stratification was implemented to ensure representation of predominantly urban and rural communities and to account for differential access to health facilities. At the district level, the principle of random selection of deaths without replacement was applied to select the allocated PPS sample of deaths. A final total of 11,984 deaths constituted the study sample, distributed across 28 districts in nine provinces from the four regions of Thailand and the three major subdistricts of Bangkok.

\section{Field implementation}

For each death selected into the study, the field protocols were as follows:

1. initial contact with household to obtain consent to participate in the study, to access medical records if the death had occurred in a hospital, and to arrange appointment for VA interview.

2. subsequent household visit to conduct VA interview.

\section{Table 1: Structure of Thai verbal autopsy questionnaires}

\begin{tabular}{|c|c|c|c|}
\hline $\begin{array}{l}\text { Deaths under one year of } \\
\text { age }\end{array}$ & Items & $\begin{array}{l}\text { Deaths aged one year and } \\
\text { over }\end{array}$ & Items \\
\hline General information & 15 & General information & 15 \\
\hline $\begin{array}{l}\text { Basic information on mother } \\
\text { of deceased }\end{array}$ & 6 & $\begin{array}{l}\text { Basic information on the } \\
\text { deceased }\end{array}$ & 10 \\
\hline $\begin{array}{l}\text { Basic information on the } \\
\text { deceased }\end{array}$ & 12 & Accident and injuries & 3 \\
\hline Accident and injuries & 2 & $\begin{array}{l}\text { Check list of symptoms, } \\
\text { including } 11 \text { items for } \\
\text { maternal deaths }\end{array}$ & 61 \\
\hline $\begin{array}{l}\text { Check list of symptoms on } \\
\text { pregnancy and delivery, and } \\
\text { on child health }\end{array}$ & 33 & $\begin{array}{l}\text { History of chronic conditions } \\
\text { and behavioural risk factors of } \\
\text { the deceased }\end{array}$ & 3 \\
\hline $\begin{array}{l}\text { Description of illness and } \\
\text { death as told by respondents }\end{array}$ & 2 & $\begin{array}{l}\text { Description of illness and } \\
\text { death as told by respondents }\end{array}$ & 2 \\
\hline Health records & 9 & Health records & 9 \\
\hline $\begin{array}{l}\text { Cause of death from death } \\
\text { certification or other } \\
\text { documents }\end{array}$ & 7 & $\begin{array}{l}\text { Cause of death from death } \\
\text { certification and other } \\
\text { documents }\end{array}$ & 7 \\
\hline Total items & 86 & Total items & 110 \\
\hline
\end{tabular}


3. review of completed questionnaire by a trained physician, leading to certification of cause of death using the international form of medical certificate of cause of death.

4. assignment of ICD codes to listed causes of death by trained coders.

5. final review by certifying physician to select the underlying cause of death and associated ICD code.

6. systematic assessment by the central study team of the accuracy of selection and coding of underlying causes of death, leading to revised cause-of-death choices in some cases.

In addition, for those deaths that had occurred in hospitals, an independent ascertainment of cause of death from medical records review was undertaken, as described elsewhere [34].

Data collection was conducted between June 2006 and July 2007, resulting in VA recall periods ranging from six to 18 months. Field activities were supported by specific training programs conducted in each province for VA interviewers, physicians, and medical coders. Paramedical staff members from district health offices and health centers were selected as field interviewers, according to specified criteria regarding qualifications and experience, with on-site supervision and quality assurance by experienced provincial staff.

Death certification from VA questionnaires and ICD coding were conducted by trained teams in Provincial Chief Medical Offices (PCMO). Family-medicine general practitioners were chosen to certify deaths from VA. Physician certification training programs were based on the principles of multiple causes of death using the standard international medical certificate of cause of death [35], which is consistently used throughout Thailand for certifying deaths in hospitals. The training programs included exercises to measure reliability of cause-of-death ascertainment using standard clinical case scenarios. These confirmed a high degree of concurrence in certification practices among participants. Each VA questionnaire was reviewed by a single physician, and if necessary, a second opinion was sought (in about $15 \%$ of cases), resulting in either a consensus diagnosis or, in the case of disagreement, the assignment of an ill-defined cause. During physician reviewer training programs, each participant was required to practice cause-of-death certification and ICD coding using 12 sample VA questionnaires, and retraining was conducted until satisfactory performance was achieved by all study reviewers. The criterion for satisfactory performance was that the ICD code for the underlying cause determined by the physician reviewer should match the code for the reference underlying cause for that case, at the ICD Mortality Tabulation List 1 level of aggregation of ICD codes [36].
Adequate quality control measures were adopted throughout data collection and processing, in the form of field supervision of VA interviews, manual verification of completeness of questionnaires and consistency in responses, and review of death certificates and ICD coding by a central team of experts from the Ministry of Public Health. Where necessary, adjudication by the central team was used to overrule decisions on selection of underlying causes at the provincial level.

In case the death had occurred in a hospital, a detailed review of the medical record was conducted [34]. The quality of clinical evidence supporting the medical records diagnoses was categorized as confirmatory or weak, based on the information available from the medical records. Review of medical records and VA for the same death was conducted strictly independently. All data from VA-based death certificates, the medical record review diagnoses, and essential variables from registration data, including the ICD code for the underlying cause of death, were entered into a statistical database for analysis.

\section{Statistical analyses}

Underlying causes of death from each of the three sources (registration, VA, and medical record review) were aggregated to the WHO Mortality Tabulation List 1 [36]. Given the large proportion of deaths classified to ill-defined causes in the registration data, the allocation of these deaths to specific causes in the study sample was of primary interest. Further analyses were also conducted to assess misallocation across specified causes. The overall implications of the findings from VA ascertainment of causes of deaths outside hospitals in Thailand were assessed through an analysis of net changes to cause-specific mortality fractions for leading causes.

The validity of the VA methods used in this study was analysed in terms of the sensitivity of VA diagnoses as compared to medical records diagnoses for each of 2,558 deaths for which medical records were available. Performance characteristics of VA in terms of over- or underdiagnoses of specific causes of death were assessed through analyses of net differences in cause-specific mortality proportions between reference diagnoses and VA diagnoses in the validation sample. Additional descriptive analyses were conducted to understand the patterns of misclassification resulting in these biases in the performance of VA.

The observed biases in the performance of VA methods were used to adjust the findings from application of VA in the verification study. The numbers of deaths identified from each cause in the verification study were adjusted by misclassification patterns for the same cause as observed in the validation study as follows: 
$\operatorname{Adjusted~deaths}(\mathbf{k})=\sum_{k=1}^{k=103} \operatorname{Verstudydeaths}(j) * \operatorname{ValstudyMRprop}(j k)$

where Verstudydeaths $(j)$ is the number of deaths identified with cause $j$ in the verification study; and

ValstudyMRprop ( $j k$ ) is the proportion of VA deaths from cause $j$ in the validation sample that were classified to a reference diagnosis $k$ based on medical records review.

Adjusted deaths ( $k$ ) is the estimate of deaths in the verification study sample due to cause $k$, and is the sum of the product of the above two terms across all deaths in the study sample for which reference diagnoses were available.

Finally, these adjusted numbers of deaths from each cause were used to derive estimates of cause-specific mortality for deaths outside hospitals in Thailand in 2005 by sex and age, aggregated across three broad age groups: $15-49$ years, 50-74 years, and 75 years and over.

\section{Results}

Out of the initial study sample of 11,984 deaths, VA methods were successfully applied in 9,817 cases (see Table One in [28]). VA interviews were completed for 6,328 out of 7,340 deaths in the study sample that had occurred outside hospitals, yielding the set of VA diagnoses for the verification study. Out of 4,644 deaths in the study sample that had occurred in hospitals, VA diagnoses were achieved for 3,489. However, corresponding medical record review diagnoses were only available in 2,558 cases, and these constituted the eventual matched sample for the VA validation study.

\section{Verification of cause for deaths outside hospitals}

The observed response rate for deaths outside hospitals was $86 \%(6,328 / 7,340)$, approximately what was expected from the pilot study. Table 2 compares the age and sex distribution of deaths from the sampling frame (registration data for deaths outside hospitals) with the age-sex distribution of the field sample.

Overall, the two sets of distributions are very similar. The slightly lower proportions of deaths in the field sample at younger ages are unlikely to significantly bias the study results because the total number of deaths at these ages in Thailand is comparatively small [37].

Similarly, the sampling procedure appears not to have introduced any substantial biases according to cause of death. Figure 1 shows the comparison between the proportionate mortality distributions of registered cause for the 30 leading causes of death from the sampling frame and from the field sample. The close concordance between the two distributions suggests that the $14 \%$ of cases lost to follow up were largely nondifferential by cause.

During data processing, the central team of experts noted that provincial coders had incorrectly coded the underlying cause in $22 \%$ of cases. However, in only $4 \%$ of cases did the resulting change in ICD code lead to an alteration of the ICD Mortality Tabulation List 1 category to which the death had been assigned (see Figure Two in [28] for details). This indicates that in general, the quality of certification and coding was of adequate quality.

The application of VA methods vastly improved the assignment of causes of death in the study sample compared with VR. In particular, the proportion of ill-defined causes was reduced from more than $53 \%$ to about $7 \%$. At ages below 50 years, there were 238 deaths classified to ill-defined causes in the registration data for the field sample (185 males, 53 females). Among males, 13\% were reassigned to HIV/AIDS by VA, and another estimated $7 \%$ to each of ischemic heart disease, stroke, other heart diseases, transport accidents, and alcohol abuse.

Table 2: Comparisons of age-sex distribution of deaths from registration data and the field sample of deaths outside hospital, Thailand, 2005

\begin{tabular}{|c|c|c|c|c|}
\hline \multirow[b]{3}{*}{ Age Group } & \multicolumn{2}{|c|}{ Males } & \multicolumn{2}{|c|}{ Females } \\
\hline & \multicolumn{2}{|c|}{$\%$ of deaths } & \multicolumn{2}{|c|}{$\%$ of deaths } \\
\hline & $\begin{array}{c}\text { Vital } \\
\text { Registration }\end{array}$ & $\begin{array}{c}\text { Field } \\
\text { Sample }\end{array}$ & $\begin{array}{c}\text { Vital } \\
\text { Registration }\end{array}$ & $\begin{array}{c}\text { Field } \\
\text { Sample }\end{array}$ \\
\hline$<14$ years & 2.3 & 2.1 & 2.1 & 1.4 \\
\hline $15-49$ years & 30.4 & 26.3 & 14.5 & 13.6 \\
\hline $50-74$ years & 39.8 & 39.7 & 36.6 & 36 \\
\hline$>75$ years & 27.5 & 31.9 & 46.8 & 49 \\
\hline All ages (100\%) & 143,021 & $3525^{*}$ & 111,822 & $2796^{*}$ \\
\hline
\end{tabular}

*Excluding 2 male and 5 female deaths for which age could not be verified 
Only about $11 \%$ of adult male deaths aged 50 and over and $15 \%$ of female deaths in that age group that were originally classified as ill-defined remained so after the verification study (Tables 3 and 4). At ages 50-74 years, ill-defined deaths were reallocated by VA across a broad range of noncommunicable diseases in both males and females (Tables 3 and 4). Among the elderly (75 years and over), several such deaths were identified by VA to be due to communicable diseases, mainly tuberculosis, diarrheal diseases, and pneumonia, in addition to noncommunicable diseases. The inability of VA to ascertain specific causes for about $10 \%$ to $15 \%$ of deaths above age 50 may well have been due to the absence of clear symptom patterns for many deaths at these ages. Nonetheless, the vast reduction in diagnoses of no public health value following VA strongly suggests that the method could and should be applied routinely to all home deaths in Thailand.

Along with the substantial reduction in the proportion of deaths originally assigned to ill-defined causes, the study also identified several important diagnostic differences among deaths assigned to specified causes in the vital registration data. Table 5 provides a summary of the extent of misclassification for the 20 leading causes of deaths outside hospitals in the study sample.

In addition to ill-defined conditions, a clear majority of deaths from several "other" categories were also reallocated to specific causes. The low kappa scores $(<0.4)$ for these, as well as some specific categories such as COPD, diabetes, and ischemic heart disease, indicate the low agreement between registration and VA data for these causes, taking into account the possibility of such agreement by chance. The observed kappa scores for some specific categories such as site-specific cancers and external causes at best suggest a moderate degree of agreement (0.4 to 0.7 ). To the extent that the VA diagnoses may be considered more accurate, given the detailed process for data collection, cause-of-death ascertainment, and selection and coding of underlying causes of death, these findings suggest poor reliability of causes of death in the registration data for nonhospital deaths from both specific and nonspecific causes.

Overall, the large numbers of deaths reclassified by VA from ill-defined causes and "other" categories result in an increase in the proportions of deaths ultimately classified

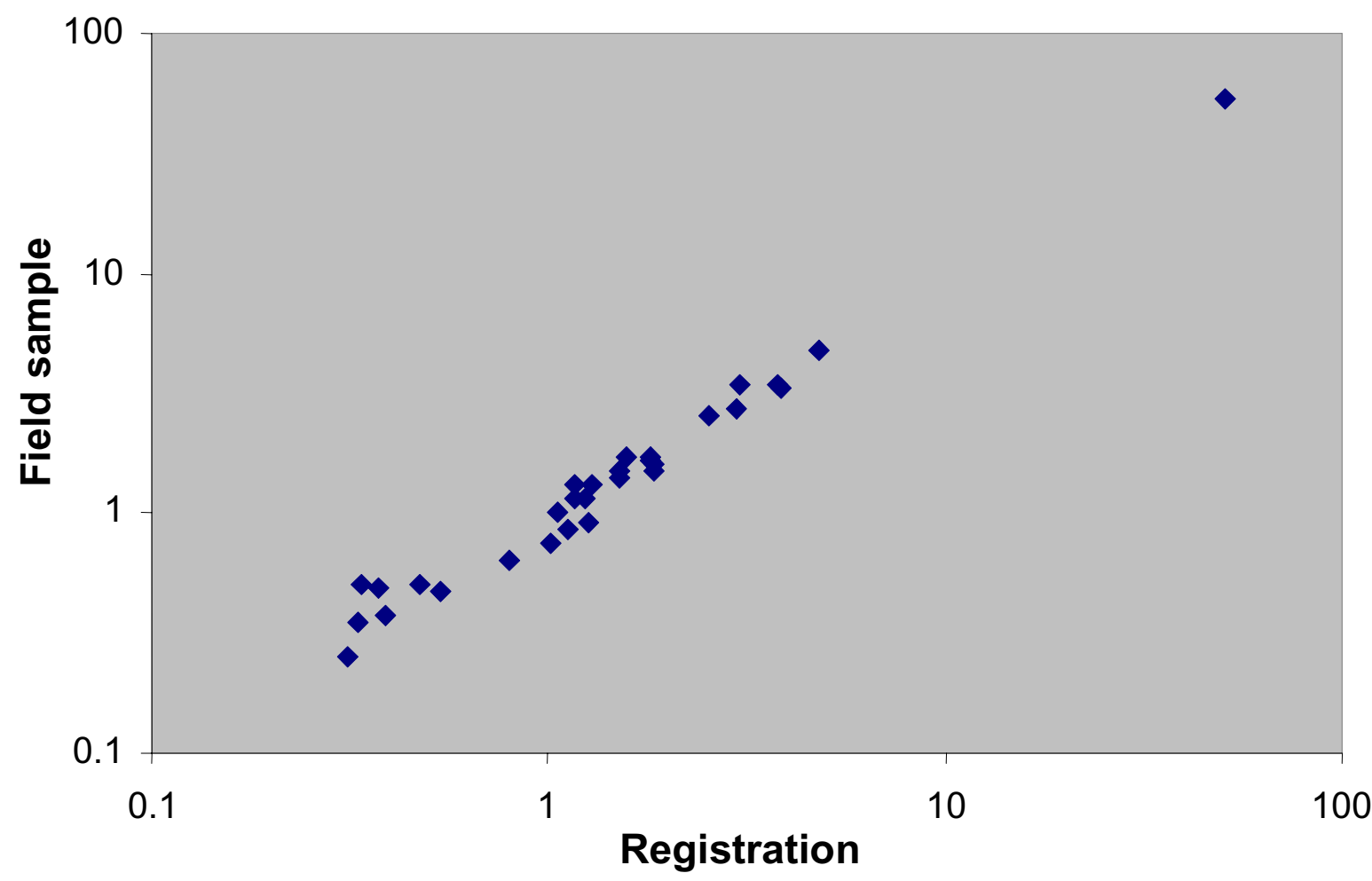

Figure 1 Comparison of cause-specific mortality proportions from registration data with registered causes in the field sample, home deaths, Thailand, 2005. Values on both axes plotted on a logarithmic scale. Causes include those listed in Table 5, plus septicemia, assault, hypertensive heart diseases, other infectious diseases, other digestive disorders, brain tumours, leukemia, breast cancer, cervical cancer, and colorectal cancer. 
Table 3: Proportionate reallocation (in \%) by VA to specific causes for deaths coded to ill defined conditions (R00-R99) in the study sample for males, Thailand, 2005

\begin{tabular}{|c|c|c|c|}
\hline Cause & $50-74$ yrs & $75+$ yrs & Total \\
\hline Cerebrovascular diseases & 7.1 & 9.2 & 16.3 \\
\hline $\begin{array}{l}\text { Chronic lower respiratory } \\
\text { diseases }\end{array}$ & 3.4 & 7.4 & 10.8 \\
\hline Ischemic heart disease & 4.5 & 3.2 & 7.7 \\
\hline Diabetes mellitus & 2.3 & 2.3 & 4.6 \\
\hline Other genitourinary diseases & 1.0 & 3.1 & 4.1 \\
\hline Other heart diseases & 1.6 & 2.4 & 4.0 \\
\hline Liver cancer & 1.7 & 2.1 & 3.8 \\
\hline Lung cancer & 1.7 & 1.9 & 3.6 \\
\hline Tuberculosis & 1.2 & 2.0 & 3.2 \\
\hline Hypertensive diseases & 0.7 & 1.7 & 2.4 \\
\hline Pneumonia & 0.6 & 1.7 & 2.3 \\
\hline Other digestive diseases & 0.6 & 1.2 & 1.8 \\
\hline Diarrhoeal diseases & 0.3 & 1.4 & 1.7 \\
\hline Liver diseases & 1.0 & 0.3 & 1.4 \\
\hline Other specified causes & 8.5 & 12.9 & 21.4 \\
\hline Ill defined conditions & 2.3 & 8.5 & 10.9 \\
\hline Total (\%) & 38.6 & 61.4 & 100.0 \\
\hline Total deaths & 561 & 892 & 1453 \\
\hline
\end{tabular}

to specific causes such as HIV/AIDS (from $1.4 \%$ to $4.4 \%$ ), ischemic heart disease (IHD) (from $0.9 \%$ to $5.5 \%$ ), stroke (from $1.6 \%$ to $10.9 \%$ ), and transport accidents ( from $2.7 \%$ to $5.2 \%$ ). These findings, however, need to be interpreted in the context of the performance characteristics of VA, as inferred from the validation study.

\section{Validation of VA methods}

The reliability of findings from verification of registration data using VA methods is inherently dependent on the validity of the VA in the Thai context. The results from the validation sample of 2,558 deaths for which diagnoses from medical records review as well as VA were available, shown in Table 6, reveal several interesting findings. First, sensitivity scores were good ( $>75 \%$ ) for some site-specific cancers and most external causes, indicating that if a death is diagnosed by VA to be from these causes, it is likely to be actually due to that cause. However, sensitivity was average (50\%-75\%) for major causes of death such HIV/AIDS, cerebrovascular and ischemic heart diseases, COPD, and diabetes.

Sensitivity was poor $(<50 \%)$ for deaths from the "other" categories, as might be expected, but was also poor for specific causes such as tuberculosis, hypertensive diseases, and pneumonia. While compensatory misclassification patterns within the validation sample tend to minimize the impact of these poor sensitivity scores on the net changes to cause-specific mortality proportions, as seen in the case of major causes such as ischemic heart disease, cerebrovascular disease, and COPD, this is not the case for other causes. Overall, VA tends to overdiagnose important causes such as diabetes, liver cancer, and tuberculosis, while undercounting deaths from HIV/ AIDS, liver diseases, genitourinary (essential renal), and digestive system disorders, and, interestingly, pneumonia. These findings have important implications when using VA validation results to adjust findings from the verification study.

Table 7 shows the detailed misclassification patterns for important causes of death that result in these changes to cause-specific mortality proportions in the validation study sample. Almost all deaths classified to HIV/AIDS by VA were confirmed upon medical record review (116 out of 123 deaths), signifying a very high positive predictive value. However, another 75 deaths were classified to HIV/AIDS from other infectious conditions as well as noncommunicable diseases, indicating poor sensitivity as well as an undercount of HIV/AIDS by VA by about 35\%. On the other hand, only $45 \%$ of deaths classified by VA to diabetes were confirmed (low PPV), with the others actually being cases of ischemic heart disease (13\%), stroke $(8 \%)$, renal failure $(6 \%)$, and other conditions. Overall, the 
Table 4: Proportionate reallocation (in\%) by VA to specific causes for deaths coded to ill defined conditions (R00-R99) in the study sample for females, Thailand, 2005

\begin{tabular}{|c|c|c|c|}
\hline Cause & $50-74$ yrs & $75+$ yrs & Total \\
\hline Cerebrovascular diseases & 3.3 & 12.0 & 15.4 \\
\hline Ischemic heart diseases & 2.5 & 5.0 & 7.5 \\
\hline Diabetes mellitus & 3.2 & 4.1 & 7.3 \\
\hline $\begin{array}{l}\text { Chronic lower respiratory } \\
\text { diseases }\end{array}$ & 1.7 & 3.0 & 4.6 \\
\hline Hypertensive diseases & 1.3 & 3.0 & 4.3 \\
\hline Other heart diseases & 0.5 & 3.5 & 4.0 \\
\hline Other genitourinary diseases & 1.1 & 2.0 & 3.2 \\
\hline Pneumonia & 0.3 & 2.7 & 3.0 \\
\hline Diarrhoeal diseases & 0.5 & 2.3 & 2.8 \\
\hline Falls & 0.4 & 1.7 & 2.2 \\
\hline Other digestive diseases & 0.8 & 1.3 & 2.1 \\
\hline Liver cancer & 0.8 & 1.1 & 2.0 \\
\hline Other cancers & 1.3 & 0.7 & 2.0 \\
\hline Muscluloskeletal disorders & 0.7 & 1.3 & 2.0 \\
\hline Other specified causes & 6.5 & 15.3 & 21.8 \\
\hline Ill defined conditions & 1.4 & 14.5 & 15.8 \\
\hline Total (\%) & 26 & 74 & 100.0 \\
\hline Total deaths & 439 & 1221 & 1660 \\
\hline
\end{tabular}

number of deaths classified to other conditions by VA that were actually found to be due to diabetes upon MR review were not as many as the VA misdiagnoses of diabetes, indicating that VA overcounts deaths from diabetes. Finally, although the difference in cause-specific mortality proportions from VA and MR diagnoses for ischemic heart disease is negligible, the matrix shows profound misclassification, with 50\% of VA diagnoses of IHD being incorrect, and an equal number of deaths classified to other causes by VA actually being due to IHD upon medical record review.

These and other misclassification patterns observed in Table 7 provide evidence on the biases that result from the use of VA in cause-of-death ascertainment in the Thai context. Accordingly, the findings from the validation study were applied to adjust for overcount or undercount by VA in the verification study, under the assumption that these performance characteristics of VA derived from deaths in the hospital sample are applicable for deaths outside hospitals in Thailand.

Tables 8 and 9 show the final estimates of cause-specific mortality by age and sex for nonhospital deaths in Thailand after this further adjustment. Although deaths from ill-defined conditions are still the leading cause of nonhospital deaths at all ages in males and females, the magnitude of this category has been substantially reduced from the more than $50 \%$ observed in the registration data. Stroke, IHD, HIV/AIDS, and chronic lower respiratory diseases are leading causes of out-of-hospital deaths for both sexes, as are transport accidents for men and diabetes mellitus for women. These findings are similar to the mortality patterns derived for the sample of deaths that had occurred in hospitals [34] and reinforce the need for appropriate policy responses. This pattern would not have been at all evident from the raw, uncorrected registration diagnoses.

\section{Discussion}

Thailand is one of several countries that has a reasonably functional vital statistics system, yet the data it produces are of limited public health utility. This largely arises from the lack of medical opinion as to the registered cause of most deaths outside hospitals that constitute the majority of deaths in these countries. The reliance on lay reporting of the cause of death by relatives of the deceased leads to large numbers of such deaths being assigned to illdefined or nonspecific causes, and contributes to uncertainty in the data on specific causes as well. In Thailand, local civil registrars are required to inquire about medical evidence on the cause of death from relatives at the time of death registration, usually discharge records from previous hospitalizations or notes from medical consulta- 
Table 5: Misclassification patterns suggested by verbal autopsy among the study sample of deaths outside hospitals, Thailand, 2005

\begin{tabular}{|c|c|c|c|c|c|c|}
\hline \multirow[b]{2}{*}{ Cause } & \multirow[b]{2}{*}{$\begin{array}{c}\text { As recorded } \\
\text { in VR }\end{array}$} & \multicolumn{3}{|c|}{ Verbal autopsy diagnoses (VA) } & \multirow[b]{2}{*}{$\begin{array}{l}\text { Final total } \\
\text { (VA) }\end{array}$} & \multirow[b]{2}{*}{ Kappa } \\
\hline & & $\begin{array}{l}\text { Agreement } \\
\text { with VR }\end{array}$ & $\begin{array}{l}\text { Assigned to } \\
\text { other cause }\end{array}$ & $\begin{array}{l}\text { Assigned } \\
\text { from other } \\
\text { cause }\end{array}$ & & \\
\hline Ill defined conditions & 3371 & 441 & 2930 & 32 & 473 & 0.11 \\
\hline Other cancers & 307 & 45 & 262 & 75 & 120 & 0.19 \\
\hline $\begin{array}{l}\text { Other genitourinary } \\
\text { diseases }\end{array}$ & 218 & 85 & 133 & 137 & 222 & 0.36 \\
\hline $\begin{array}{l}\text { All other external } \\
\text { causes }\end{array}$ & 217 & 21 & 196 & 82 & 103 & 0.11 \\
\hline Liver cancer & 213 & 178 & 35 & 237 & 415 & 0.55 \\
\hline Transport accidents & 175 & 168 & 7 & 165 & 333 & 0.65 \\
\hline Diabetes mellitus & 161 & 104 & 57 & 274 & 378 & 0.36 \\
\hline $\begin{array}{l}\text { Other respiratory } \\
\text { diseases }\end{array}$ & 110 & 1 & 109 & 20 & 21 & 0.01 \\
\hline Diseases of the liver & 108 & 29 & 79 & 84 & 113 & 0.24 \\
\hline Lung cancer & 104 & 71 & 33 & 121 & 192 & 0.47 \\
\hline $\begin{array}{l}\text { Cerebrovascular } \\
\text { diseases }\end{array}$ & 103 & 64 & 39 & 626 & 690 & 0.14 \\
\hline $\begin{array}{l}\text { Other nervous } \\
\text { system disorders }\end{array}$ & 95 & 14 & 81 & 68 & 82 & 0.15 \\
\hline HIV/AIDS & 94 & 86 & 8 & 172 & 258 & 0.48 \\
\hline Drowning & 90 & 71 & 19 & 17 & 88 & 0.79 \\
\hline Suicide & 83 & 67 & 16 & 49 & 116 & 0.67 \\
\hline $\begin{array}{l}\text { Chronic lower } \\
\text { respiratory diseases }\end{array}$ & 82 & 53 & 29 & 310 & 363 & 0.22 \\
\hline $\begin{array}{l}\text { Respiratory } \\
\text { tuberculosis }\end{array}$ & 72 & 28 & 44 & 108 & 136 & 0.26 \\
\hline Other heart diseases & 72 & 13 & 59 & 162 & 175 & 0.09 \\
\hline Pneumonia & 63 & 7 & 56 & 108 & 115 & 0.07 \\
\hline $\begin{array}{l}\text { Ischemic heart } \\
\text { disease }\end{array}$ & 59 & 28 & 31 & 322 & 350 & 0.12 \\
\hline All other causes & 531 & & & & 1585 & \\
\hline Total deaths & 6328 & & & & 6328 & \\
\hline
\end{tabular}

tions during the illness preceding death. However, there is no systematic approach to such inquiry, and it is not adopted consistently across the country, adding to the uncertainty in registration data on causes of death.

Our study was designed to develop and test a detailed VA data collection instrument, including a comprehensive list of structured questions on symptoms and other relevant medical history, open text descriptions as told by the informant, as well as any relevant diagnostic information or treatment history available within the household. Our VA procedures also enabled us to ascertain the appli- cability of standard disease or condition-specific diagnostic guidelines that have been developed to help identify probable causes of death from VA responses [29,38]. Our data collection methods and the application of such diagnostic guidelines enabled ascertainment of the probable cause of death for the vast majority of deaths in the study sample. Feedback from physician reviewers of the VA responses suggested that the open narrative component of the questionnaire was essential in cause-of-death determination. Further research is required to determine whether local health personnel could be trained to apply 
Table 6: Validation characteristics of verbal autopsy procedures for 20 leading causes of hospital deaths in the study sample, Thailand, 2005

\begin{tabular}{|c|c|c|c|c|c|}
\hline \multirow[t]{2}{*}{ Cause of death } & \multirow{2}{*}{$\begin{array}{l}\text { Medical record } \\
\text { (MR) diagnoses }\end{array}$} & \multirow{2}{*}{$\begin{array}{l}\text { Verbal autopsy } \\
\text { (VA) diagnoses }\end{array}$} & \multicolumn{3}{|c|}{ Validation scores for VA } \\
\hline & & & Sensitivity & PPV & $\begin{array}{l}\text { CSMF change in } \\
\text { VA (\%)* }\end{array}$ \\
\hline $\begin{array}{l}\text { Cerebrovascular } \\
\text { diseases }\end{array}$ & 269 & 285 & 69.1 & 65.3 & 6.5 \\
\hline Diabetes mellitus & 158 & 224 & 63.9 & 45.1 & 41.8 \\
\hline $\begin{array}{l}\text { Ischemic heart } \\
\text { disease }\end{array}$ & 203 & 199 & 49.8 & 50.8 & -1.9 \\
\hline $\begin{array}{l}\text { Transport } \\
\text { accidents }\end{array}$ & 185 & 199 & 97.8 & 91.0 & 7.6 \\
\hline $\begin{array}{l}\text { Chronic lower } \\
\text { respiratory } \\
\text { diseases }\end{array}$ & 143 & 147 & 61.5 & 59.9 & 2.9 \\
\hline HIV/AIDS & 191 & 123 & 60.7 & 94.3 & -35.6 \\
\hline Lung cancer & 84 & 99 & 79.8 & 67.7 & 17.9 \\
\hline $\begin{array}{l}\text { Diseases of the } \\
\text { liver }\end{array}$ & 112 & 93 & 44.6 & 53.8 & -17.1 \\
\hline $\begin{array}{l}\text { Malignant } \\
\text { neoplasm of liver }\end{array}$ & 65 & 88 & 78.5 & 58.0 & 35.3 \\
\hline $\begin{array}{l}\text { Other } \\
\text { genitourinary } \\
\text { diseases }\end{array}$ & 107 & 86 & 30.8 & 38.4 & -18.8 \\
\hline $\begin{array}{l}\text { Other heart } \\
\text { diseases }\end{array}$ & 64 & 65 & 15.6 & 15.4 & 0.0 \\
\hline Pneumonia & 85 & 61 & 21.2 & 29.5 & -28.2 \\
\hline $\begin{array}{l}\text { Hypertensive } \\
\text { diseases }\end{array}$ & 58 & 54 & 12.1 & 13.0 & -6.6 \\
\hline $\begin{array}{l}\text { Respiratory } \\
\text { tuberculosis }\end{array}$ & 31 & 46 & 32.3 & 21.7 & 48.8 \\
\hline Colorectal cancer & 33 & 45 & 84.8 & 62.2 & 36.4 \\
\hline Falls & 35 & 39 & 60.0 & 53.8 & 11.7 \\
\hline Assault & 33 & 38 & 90.9 & 78.9 & 15.5 \\
\hline $\begin{array}{l}\text { Remainder of } \\
\text { malignant } \\
\text { neoplasms }\end{array}$ & 37 & 34 & 27.0 & 29.4 & -8.3 \\
\hline $\begin{array}{l}\text { Other digestive } \\
\text { disorders }\end{array}$ & 53 & 34 & 20.8 & 32.4 & -36.1 \\
\hline $\begin{array}{l}\text { All other external } \\
\text { causes }\end{array}$ & 30 & 34 & 50.0 & 44.1 & 16.7 \\
\hline All other causes & 582 & 565 & & & \\
\hline Total deaths & 2558 & 2558 & & & \\
\hline
\end{tabular}

*indicates the change in cause-specific mortality fractions (CSMF) from VA:

+ ve change indicates over diagnosis by VA;

- ve change indicates under diagnosis by VA 
Table 7: Discrepancies observed between verbal autopsy diagnoses and medical record review in the validation sample

\begin{tabular}{|c|c|c|c|c|c|c|c|c|c|c|c|c|c|c|c|c|c|}
\hline Causes of death & Medi & recorc & iagn & & & & & & & & & & & & & & \\
\hline $\begin{array}{l}\text { Verbal autopsy } \\
\text { diagnoses }\end{array}$ & 5 & 20 & 25 & 52 & 66 & 67 & 68 & 69 & 74 & 76 & 77 & 79 & 80 & 81 & 84 & $\begin{array}{r}\text { All other } \\
\text { causes }\end{array}$ & Total \\
\hline Tuberculosis (5) & 10 & 9 & 2 & & & 1 & 1 & 1 & 3 & 6 & 4 & & 2 & & 3 & 4 & 46 \\
\hline HIV/AIDS (20) & & 116 & & & & & & & & & & & 2 & & 1 & 4 & 123 \\
\hline $\begin{array}{l}\text { Other infectious } \\
\text { diseases (25) }\end{array}$ & 1 & 8 & 8 & & & & & & 2 & 1 & & & 1 & 1 & 1 & 6 & 29 \\
\hline Diabetes (52) & & 3 & 1 & 101 & 5 & 29 & 3 & 19 & 7 & 6 & 2 & 1 & 7 & 3 & 13 & 24 & 224 \\
\hline $\begin{array}{l}\text { Hypertensive } \\
\text { diseases (66) }\end{array}$ & 1 & & & 7 & 7 & 10 & 1 & 5 & 5 & 1 & 1 & & & 2 & 9 & 5 & 54 \\
\hline $\begin{array}{l}\text { Ischemic heart } \\
\text { diseases (67) }\end{array}$ & 2 & 4 & 1 & 14 & 11 & 101 & 13 & 6 & 4 & 7 & & & 4 & 2 & 7 & 23 & 199 \\
\hline $\begin{array}{l}\text { Other heart } \\
\text { diseases (68) }\end{array}$ & & & & 1 & 4 & 17 & 10 & 7 & 3 & 2 & 1 & & 1 & & 2 & 16 & 64 \\
\hline $\begin{array}{l}\text { Cerebrovascular } \\
\text { diseases (69) }\end{array}$ & 2 & 1 & 1 & 13 & 3 & 15 & 10 & 184 & 9 & 5 & 1 & 1 & 3 & 1 & 4 & 36 & 285 \\
\hline Pneumonia (74) & 2 & 5 & & 2 & 4 & 1 & 3 & 2 & 18 & 6 & 1 & & 1 & 2 & 3 & 11 & 61 \\
\hline COPD (76) & 4 & 4 & 2 & & 2 & 7 & 4 & 4 & 4 & 88 & 1 & 1 & 2 & 2 & 6 & 16 & 147 \\
\hline $\begin{array}{l}\text { Other respiratory } \\
\text { diseases (77) }\end{array}$ & 1 & 2 & & & 1 & & & 1 & 2 & 2 & 3 & & 1 & 1 & 2 & 1 & 17 \\
\hline Peptic ulcer (79) & & 1 & 1 & & & 3 & & & 1 & 1 & 1 & 10 & 5 & 5 & 2 & 2 & 32 \\
\hline Liver diseases (80) & & 7 & & 1 & & 2 & 2 & 3 & 3 & 1 & 1 & & 50 & 7 & 2 & 14 & 93 \\
\hline $\begin{array}{l}\text { Other digestive } \\
\text { diseases (81) }\end{array}$ & & 1 & 1 & 1 & & & & 3 & 1 & & & & 2 & 11 & 2 & 10 & 34 \\
\hline $\begin{array}{l}\text { Genitourinary } \\
\text { diseases (84) }\end{array}$ & & 1 & & 5 & 15 & 1 & 3 & 2 & 2 & & & 2 & 3 & 3 & 33 & 18 & 86 \\
\hline All other causes & 8 & 29 & 8 & 13 & 6 & 16 & 14 & 32 & 21 & 17 & 5 & 1 & 28 & 13 & 17 & 836 & 1064 \\
\hline Total & 31 & 191 & 25 & 158 & 58 & 203 & 64 & 269 & 85 & 143 & 21 & 16 & 112 & 53 & 107 & 1022 & 2558 \\
\hline
\end{tabular}


Table 8: Cause-specific mortality estimates (in\%) by age for deaths outside hospitals in the study sample for males, Thailand, 2005

\begin{tabular}{|c|c|c|c|c|c|}
\hline \multirow[t]{2}{*}{ Cause of death } & \multicolumn{4}{|c|}{ Age group } & \multirow[t]{2}{*}{ Total } \\
\hline & $<15$ yrs & $15-49$ yrs & $50-74$ yrs & $>75$ yrs & \\
\hline Cerebrovascular diseases & & 0.7 & 4.5 & 3.6 & 8.9 \\
\hline Transport accidents & 0.5 & 5.0 & 1.2 & 0.1 & 6.8 \\
\hline HIV/AIDS & 0.2 & 5.7 & 0.6 & $<0.1$ & 6.4 \\
\hline $\begin{array}{l}\text { Chronic lower respiratory } \\
\text { diseases }\end{array}$ & & 0.3 & 2.4 & 3.2 & 6.0 \\
\hline Ischemic heart disease & & 0.6 & 3.5 & 1.7 & 5.9 \\
\hline Liver cancer & & 0.8 & 3.1 & 0.9 & 4.8 \\
\hline Diseases of the liver & & 1.4 & 2.1 & 1.1 & 4.5 \\
\hline Lung cancer & & 0.3 & 2.2 & 1.0 & 3.4 \\
\hline Other genitourinary diseases & & 0.2 & 1.4 & 1.6 & 3.2 \\
\hline Diabetes & & 0.2 & 1.9 & 0.9 & 3.0 \\
\hline Suicide & & 1.8 & 0.8 & 0.1 & 2.8 \\
\hline Pneumonia & & 0.4 & 0.7 & 1.2 & 2.3 \\
\hline Drowning & 0.6 & 0.8 & 0.4 & 0.1 & 2.0 \\
\hline All other external causes & & 0.9 & 0.7 & 0.4 & 1.9 \\
\hline Other heart diseases & & 0.4 & 0.7 & 0.8 & 1.9 \\
\hline Other malignant neoplasms & & 0.3 & 1.0 & 0.4 & 1.6 \\
\hline Assault & & 1.1 & 0.4 & $<0.1$ & 1.5 \\
\hline Other digestive disorders & & 0.2 & 0.6 & 0.7 & 1.4 \\
\hline Hypertensive diseases & & 0.1 & 0.6 & 0.7 & 1.4 \\
\hline All other specified causes & 0.7 & 3.8 & 8.3 & 5.8 & 18.5 \\
\hline III defined conditions & & 1.3 & 2.8 & 7.7 & 11.8 \\
\hline Total deaths (\%) & 2.1 & 26.3 & 39.7 & 31.9 & 100 \\
\hline Total deaths & 73 & 927 & 1398 & 1127 & 3523 \\
\hline
\end{tabular}

these diagnostic guidelines for cause-of-death ascertainment, with a view toward routinely implementing such procedures to improve the quality of data on causes of death in registration data. There is some basis to conclude that they might. The provincial health authorities in Ubolrajthani (the province with the largest sample of deaths in this study) are already planning to implement the methods developed in this study to collect data on all deaths in the province in 2009 (Yawarat P., personal communication). The findings from their experiment will provide important evidence on the broader applicability and utility of these methods for improving cause-of-death diagnoses.

The most important limitation of our study lies in the underlying uncertainty of VA methods arising from recall and/or information bias in the responses to the VA interview, as well as the potential for inconsistency in the application of diagnostic guidelines by physician review- ers. Although we conducted a concurrent validation study, there could be selection bias in the hospital deaths included in the validation study because the characteristics of cases where the death occurred in a hospital may not be the same as for deaths from the same cause that occurred outside hospitals [39]. This selection bias could affect our assumption that the VA performance characteristics from the validation study are applicable in adjusting the findings from the verification study.

On the other hand, there could be certain cultural or language-specific issues that influence the comprehension of (and responses to) specific VA questions. These issues could be common to Thai society in general, and therefore influence VA responses for deaths in hospitals and homes in a similar manner, resulting in systematic biases common to all application of VA in Thailand. These issues need to be explored through in-depth sociological and anthropological research. In this study, we 
Table 9: Cause-specific mortality estimates (in\%) by age for deaths outside hospitals in the study sample for females, Thailand, 2005

\begin{tabular}{|c|c|c|c|c|c|}
\hline \multirow[t]{2}{*}{ Cause of death } & \multicolumn{4}{|c|}{ Age group } & \multirow[t]{2}{*}{ Total } \\
\hline & $<15$ yrs & $15-49$ yrs & $50-74$ yrs & $>75$ yrs & \\
\hline $\begin{array}{l}\text { Cerebrovascular } \\
\text { diseases }\end{array}$ & & 0.4 & 3.3 & 7.3 & 11.0 \\
\hline Diabetes & & 0.4 & 4.2 & 2.6 & 7.2 \\
\hline $\begin{array}{l}\text { Ischemic heart } \\
\text { disease }\end{array}$ & & 0.3 & 2.5 & 3.8 & 6.5 \\
\hline HIV/AIDS & 0.1 & 4.3 & 0.1 & 0.1 & 4.5 \\
\hline $\begin{array}{l}\text { Other } \\
\text { genitourinary } \\
\text { diseases }\end{array}$ & & 0.4 & 2.3 & 1.7 & 4.4 \\
\hline $\begin{array}{l}\text { Chronic lower } \\
\text { respiratory } \\
\text { diseases }\end{array}$ & & 0.1 & 1.6 & 1.9 & 3.8 \\
\hline Pneumonia & & 0.1 & 0.7 & 2.7 & 3.5 \\
\hline Liver cancer & & 0.5 & 2.2 & 0.7 & 3.3 \\
\hline $\begin{array}{l}\text { Hypertensive } \\
\text { diseases }\end{array}$ & & 0.1 & 1.4 & 1.6 & 3.1 \\
\hline Cervical cancer & & 0.8 & 1.8 & 0.3 & 2.9 \\
\hline $\begin{array}{l}\text { Other heart } \\
\text { diseases }\end{array}$ & & 0.1 & 0.5 & 1.8 & 2.4 \\
\hline $\begin{array}{l}\text { Other digestive } \\
\text { disorders }\end{array}$ & & 0.1 & 1.0 & 1.2 & 2.3 \\
\hline $\begin{array}{l}\text { Diseases of the } \\
\text { liver }\end{array}$ & 0.1 & 0.3 & 1.0 & 0.7 & 2.1 \\
\hline $\begin{array}{l}\text { Other malignant } \\
\text { neoplasms }\end{array}$ & & 0.2 & 1.4 & 0.5 & 2.1 \\
\hline Lung cancer & & 0.2 & 1.3 & 0.5 & 2.0 \\
\hline $\begin{array}{l}\text { Transport } \\
\text { accidents }\end{array}$ & 0.4 & 1.0 & 0.5 & 0.1 & 1.9 \\
\hline $\begin{array}{l}\text { Musculoskeletal } \\
\text { disorders }\end{array}$ & & 0.1 & 0.7 & 1.0 & 1.8 \\
\hline Falls & & $<0.1$ & 0.5 & 1.2 & 1.7 \\
\hline $\begin{array}{l}\text { All other external } \\
\text { causes }\end{array}$ & & 0.4 & 0.4 & 0.9 & 1.7 \\
\hline $\begin{array}{l}\text { All other specified } \\
\text { causes }\end{array}$ & 0.7 & 3.8 & 7.8 & 8.6 & 20.7 \\
\hline $\begin{array}{l}\text { Ill defined } \\
\text { conditions }\end{array}$ & 0.1 & 0.1 & 1.1 & 10.0 & 11.2 \\
\hline Total deaths (\%) & 1.4 & 13.6 & 36.0 & 49.0 & 100 \\
\hline Total deaths & 38 & 380 & 1002 & 1376 & 2796 \\
\hline
\end{tabular}


chose to test the utility of this additional adjustment using the validation study findings, and believe that this step yields more plausible cause-of-death estimates than without it. This is particularly apparent through the increase in the proportion of deaths from HIV/AIDS, which now approximates an independent estimate of deaths from HIV/AIDS in Thailand in 2005 developed by UNAIDS [40]. Also, the effect of gross systematic overcounting of diabetes by VA has been limited by this adjustment. For all other causes, these adjustments at best result in marginal differences to the overall estimates (see Figures Four and Five in [28]).

The development and application of VA methods specific to the Thai context are an important step toward the improvement of data quality from civil registration and vital statistics systems in Thailand. Further refinement of the questionnaire in terms of item reduction or modification would be useful, as would better methods and procedures to capture information from medical records for deaths that occur outside hospitals. This critical clinical information is likely to be available for a significant proportion of such deaths, given the better access to health care in Thailand, through universal health insurance schemes, as compared to other developing countries. Research in these areas is urgently required if there is to be an acceleration in the improvement of data quality on registered causes of death. Our study has added to the body of knowledge about the application of verbal autopsy methods in developing countries, but more importantly, has demonstrated the very significant potential of the method to reduce ignorance about the leading causes of death in populations where a large proportion of deaths occur outside hospitals.

\section{Competing interests}

The authors declare that they have no competing interests.

\section{Authors' contributions}

WP led the field work. CR designed the study along with ADL and YP. WP, CR, TA and JP contributed to data analysis. CR drafted the initial manuscript. All authors collaborated in developing the final manuscript and approved the final version.

\section{Acknowledgements \\ The authors acknowledge the support received from Ms Pumarin Poomsri and Mr Yoothana Samanmitri toward data management and project administra- tion; and secretarial assistance from Ms Melanie Kawa in preparation of the manuscripts for submission.}

\section{Author Details \\ 'School of Health Sciences, Thummathirat Open University, Bangkok, Thailand, 2School of Population Health, University of Queensland, Brisbane, Australia, ${ }^{3}$ Department of Community Medicine, Thammasat University, Pathumthani, Thailand, ${ }^{4}$ Ministry of Public Health, Bangkok, Thailand and 5 Health Information Systems Knowledge Hub, University of Queensland, Brisbane, Australia}

Received: 14 October 2009 Accepted: 18 May 2010 Published: 18 May 2010

\section{References}

1. Bureau of Planning and Strategy: Mortality Database. Bangkok: Ministry of Public Health, Thailand; 2008.

2. Tangcharoensathien V, Faramnuayphol P, Teokul W, Bundhamcharoen K Wibulpholprasert S: A critical assessment of mortality statistics in Thailand: potential for improvements. Bull World Health Organ 2006, 84:233-8.

3. Ministry of Public Health Thailand: Mortality system in Thailand. In Regional Consultation on Mortality Statistics New Delhi: WHO Regional Office for South-East Asia; 2007.

4. Choprapawon C, Porapakkham Y, Sablon O, Panjajaru R, Jhantharatat B: Thailand's national death registration reform: verifying the causes of death between July 1997 and December 1999. Asia Pac J Public Health 2005, 17:110-6.

5. Fauveau $\mathrm{V}$ : Assessing probable causes of death without death registration or certificates: a new science. Bull World Health Organ 2006, 84:246-7.

6. Garenne M, Fauveau V: Potential and limits of verbal autopsies. Bull World Health Organ 2006, 84:164.

7. Fauveau V, Koenig MA, Chakraborty J, Chowdhury Al: Causes of maternal mortality in rural Bangladesh, 1976-85. Bull World Health Organ 1988, 66:643-51.

8. Snow RW, Armstrong JR, Forster D, Winstanley MT, Marsh VM, Newton CR, Wariuru C, Mwangi I, Winstanley PA, Marsh K: Childhood deaths in Africa: uses and limitations of verbal autopsies. Lancet 1992, 340:351-5.

9. Kamali A, Wagner HU, Nakiyingi J, Sabiiti I, Kengeya-Kayondo JF, Mulder DW: Verbal autopsy as a tool for diagnosing HIV-related adult deaths in rural Uganda. Int J Epidemiol 1996, 25:679-84.

10. Kahn K, Tollman SM, Garenne M, Gear JS: Validation and application of verbal autopsies in a rural area of South Africa. Trop Med Int Health 2000, 5:824-31.

11. Setel PW, Sankoh O, Rao C, Velkoff VA, Mathers CD, Yang G, Hemed Y, Jha P, Lopez AD: Sample registration of vital events with verbal autopsy: A renewed commitment to measuring and monitoring vital statistics. Bull World Health Organ 2005, 83:611-7.

12. Gajalakshmi V, Peto R, Kanaka S, Balasubramanian S: Verbal autopsy of 48 000 adult deaths attributable to medical causes in Chennai (formerly Madras), India. BMC Public Health 2002, 2:7.

13. Etard JF, Hesran JY Le, Diallo A, Diallo JP, Ndiaye JL, Delaunay V: Childhood mortality and probable causes of death using verbal autopsy in Niakhar, Senegal, 1989-2000. Int J Epidemiol 2004, 33:1286-92.

14. Quigley MA: Commentary: Verbal autopsies--from small-scale studies to mortality surveillance systems. Int J Epidemiol 2005, 34:1087-8.

15. Jha P, Gajalakshmi V, Gupta PC, Kumar R, Mony P, Dhingra N, Peto R, RGICGHR Prospective Study Collaborators: Prospective study of one million deaths in India: rationale, design, and validation results. PLoS Med 2006, 3:e18.

16. Wang L, Yang G, Jiemin M, Rao C, Wan X, Dubrovsky G, Lopez AD: Evaluation of the quality of cause of death statistics in rural China using verbal autopsies. J Epidemio/ Community Health 2007, 61:519-26.

17. Quigley MA, Armstrong JR Schellenberg, Snow RW: Algorithms for verbal autopsies: a validation study in Kenyan children. Bull World Health Organ 1996, 74:147-54.

18. Rodriguez L, Reyes H, Tome P, Ridaura C, Flores S, Guiscafre H: Validation of the verbal autopsy method to ascertain acute respiratory infection as cause of death. Indian J Pediatr 1998, 65:579-84.

19. Benara SK, Singh P: Validity of causes of infant death by verbal autopsy. Indian J Pediatr 1999, 66:647-50.

20. Coldham C, Ross D, Quigley M, Segura Z, Chandramohan D: Prospective validation of a standardized questionnaire for estimating childhood mortality and morbidity due to pneumonia and diarrhoea. Trop Med Int Health 2000, 5:134-44.

21. Marsh DR, Sadruddin S, Fikree FF, Krishnan C, Darmstadt GL: Validation of verbal autopsy to determine the cause of 137 neonatal deaths in Karachi, Pakistan. Paediatr Perinat Epidemiol 2003, 17:132-42.

22. Chandramohan D, Maude GH, Rodrigues LC, Hayes RJ: Verbal autopsies for adult deaths: issues in their development and validation. Int J Epidemiol 1994, 23:213-22.

23. Chandramohan D, Maude GH, Rodrigues LC, Hayes RJ: Verbal autopsies for adult deaths: their development and validation in a multicentre study. Trop Med Int Health 1998, 3:436-46. 
24. Yang G, Rao C, Ma J, Wang L, Wan X, Dubrovsky G, Lopez AD: Validation of verbal autopsy procedures for adult deaths in China. Int J Epidemiol 2006, 35:741-8.

25. Setel PW, Whiting DR, Hemed Y, Chandramohan D, Wolfson LJ, Alberti KG, Lopez AD: Validity of verbal autopsy procedures for determining cause of death in Tanzania. Trop Med Int Health 2006, 11:681-96.

26. Byass $\mathrm{P}$, Huong DL, Minh HV: A probabilistic approach to interpreting verbal autopsies: methodology and preliminary validation in Vietnam. Scand J Public Health Supp/ 2003, 62:32-7.

27. Murray CJ, Lopez AD, Feehan DM, Peter ST, Yang G: Validation of the symptom pattern method for analyzing verbal autopsy data. PLoS Med 2007, 4:e327.

28. Rao C, Porapakkham Y, Pattaraarchachai J, Polprasert W, Swampunyalert Lopez AD: Verifying causes of death in Thailand: rationale and methods for empirical investigation. Popul Health Metr 2010, 8:11.

29. World Health Organization: Verbal autopsy standards: ascertaining and attributing cause of death. Geneva: World Health Organization; 2007.

30. Ministry of Public Health: Burden of Disease and Injury in Thailand: Priority setting for Policy. Bangkok: Ministry of Public Health, Thailand; 2002

31. Prasartkul P, Porapakkham Y, Wapattanawong P, Rittirong J: Development of a verbal autopsy tool for investigating cause of death. Journal of Population and Social Studies 2007, 15:1-22.

32. Setel PW, Rao C, Hemed Y, Whiting DR, Yang G, Chandramohan D, Alberti KG, Lopez AD: Core verbal autopsy procedures with comparative validation results from two countries. PLOS Med 2006, 3:e268.

33. Sample Vital Registration with Verbal Autopsy (SAVVY). Verbal autopsy Interviewer's manual [http://www.cpc.unc.edu/measure/tools/ monitoring-evaluation-systems/savvy]. MEASURE Evaluation, University of North Carolina; USA

34. Pattaraarchachai J, Rao C, Polprasert W, Porapakkham Y, Poa-in W, Singeverathum N, Lopez AD: Cause-specific mortality patterns among hospital deaths in Thailand: validating routine death certification. Popul Health Metr 2010, 8:12.

35. World Health Organization: Mortality: guidelines for certification and rules for coding. In International Statistical Classification of Diseases and Health Related Problems - Tenth Revision Volume 2: Instruction Manual Geneva: World Health Organization; 1993:30-65.

36. World Health Organization: Special tabulation lists for mortality and morbidity; Mortality tabulation list 1. In International Statistical Classification of Diseases and Health Related Problems - Tenth Revision Volume 1 Geneva: World Health Organization; 1993:1207-10.

37. Murray CIL, Laakso T, Shibuya K, Hill K, Lopez AD: Can we achieve Millennium Development Goal 4? New analysis of country trends and forecasts of under-5 mortality to 2015. Lancet 2007, 370:1040-54.

38. Sample Vital Registration with Verbal Autopsy (SAVVY). Verbal Autopsy Certifier and Coder's Manual [http://www.cpc.unc.edu/measure/tools/ monitoring-evaluation-systems/savvy]. MEASURE Evaluation, University of North Carolina; USA

39. Chandramohan D, Setel P, Quigley M: Effect of misclassification of causes of death in verbal autopsy: can it be adjusted. Int J Epidemiol 2001, 30:509-514.

40. UNAIDS: AIDS deaths in adults and children by country, 1990-2007. Report on the Global HIV/AIDS epidemic, 2008. UNAIDS/08.27E / JC1511E [http://data.unaids.org/pub/GlobalReport/2008/ 20080818 gr08 deaths 19902007 en.xls].

doi: $10.1186 / 1478-7954-8-13$

Cite this article as: Polprasert et al., Cause-of-death ascertainment for deaths that occur outside hospitals in Thailand: application of verbal autopsy methods Population Health Metrics 2010, 8:13

\section{Submit your next manuscript to BioMed Central and take full advantage of:}

- Convenient online submission

- Thorough peer review

- No space constraints or color figure charges

- Immediate publication on acceptance

- Inclusion in PubMed, CAS, Scopus and Google Scholar

- Research which is freely available for redistribution

Submit your manuscript at www.biomedcentral.com/submit
C BioMed Central 